Construir un enemigo en tiempos de neutralidad: anticomunismo y disciplinamiento detrás de los debates por el derecho de reunión en Argentina (1938-1943)

Mercedes F. López Cantera

páginas / año 12 - n² 28 Enero-Abtil / ISSN 1851-992X/ 2020

http://revistapaginas.unr.edu.ar/index.php/RevPaginas

\title{
Construir un enemigo en tiempos de neutralidad: anticomunismo y disciplinamiento detrás de los debates por el derecho de reunión en Argentina (1938-1943)
}

\author{
Constructing an enemy in times of neutrality: anticommunism \\ and disciplinary measures during the debates about Freedom of \\ Assembly in Argentina (1938-1943)
}

\author{
Mercedes F. López Cantera \\ Universidad de Buenos Aires; \\ Centro de Estudios Históricos de los Trabajadores y las Izquierdas (Argentina) \\ mercedes.lopez.cantera@gmail.com
}

\begin{abstract}
Resumen
El despliegue de la represión estatal en la Argentina realizado por la Policía de la Capital en los años treinta y en los tempranos cuarentas encontró en el llamado "enemigo comunista" un sujeto en base al cual el Estado pudo especializar y delinear distintas estrategias de disciplinamiento, que tuvieron como principal objetivo al movimiento obrero. Partiendo de esta premisa y ubicándonos en el contexto que generó el impacto de la Guerra Civil española y los comienzos de la Segunda Guerra Mundial, junto a las políticas de prescindencia y de neutralidad adoptadas por los gobiernos del período, nos proponemos analizar aquellas medidas que esa fuerza policial impartió en relación al control sobre las reuniones públicas con el objetivo de caracterizar a la lógica anticomunista presente en las herramientas de disciplinamiento dispuestas a fin de la gestión de Agustín P. Justo (1932-1938) y durante la de Roberto Ortiz y Ramón Castillo (1938-1943). Con esos objetivos abordaremos los distintos edictos policiales sobre reuniones públicas y las discusiones en torno a la aplicación de los mismos que tuvieron lugar en el Poder Legislativo, donde serán centrales las interpelaciones solicitadas por la Cámara de Diputados al Ministro del Interior Miguel Culaciati, y las diversas acciones de represión impartidas sobre el movimiento obrero entre 1938-1943 desde la Sección Especial de Represión contra el Comunismo de la Policía de la Capital.
\end{abstract}

\section{Palabras clave}

Anticomunismo; Comunismo; Represión; Movimiento obrero; Segunda Guerra Mundial

\begin{abstract}
The state repression in Argentina carried out by the Policia de la Capital in the thirties and in the early forties found in the "communist enemy" a subject on which the State could specialize and delineate different disciplinary strategies, whose main objective was the labor movement. Considering the context of the Spanish Civil War and the beginning of the
\end{abstract}

Esta obra está sujeta a la Licencia Reconocimiento-NoComercial-CompartirIgual 4.0 Internacional de Creative Commons. http://creativecommons.org/licenses/by-nc-sa/4.0/ 


\title{
Mercedes F. López Cantera
}

Second World War, and the neutralist policy adopted by the governments of the period, we propose to analyze the control policy imparted by the Police over public meetings in order to characterize the anticommunist logic of the disciplinary tools disposed in the last years of Agustín P. Justo (1932-1938) and Roberto Ortiz and Ramón Catillo (1938-1943) administrations. With these objectives we will address the different police edicts on public meetings and the discussions about its application that took place in the Legislative Power, during the interpellations to the Minister of the Interior Miguel Culaciati, and the different repression actions on the labor movement between 1938-1943 carried out by the Special Branch of the Policia de la Capital.

\section{Keywords}

Anticommunism; Communism; Repression; Labor movement; Second World War

\begin{abstract}
"Para conjurar estos peligros posibles es indispensable que el Estado en ejercicio de su poder de policía adopte las disposiciones conducentes para contener todas las extralimitaciones y desbordes atentatorios a nuestro régimen institucional, para lo cual el goce del derecho de reunión debe reducirse a sus menores límites (...) Por razones de salud pública el Poder Ejecutivo no habrá de facilitar con su inercia y menos con su complacencia, la penetración de los comunistas en los partidos políticos y las organizaciones obreras. Los vigilará muy de cerca, sabiendo que no desean nuestras libertades por lo que ellas significan como garantía de la personalidad humana, sino como escudo de sus propósitos de dominación política..."
\end{abstract}

Mensaje del Ministro del Interior a la Honorable Cámara de Diputados de la Nación, 12 de marzo de 1941

En los albores de la década de 1940, tuvo lugar en la Cámara de Diputados de la Nación un conjunto de debates relacionados a las disposiciones que regulaban la realización de encuentros o actividades en espacios públicos. De acuerdo a lo referido por distintos autores, el control sobre el derecho de reunión se había constituido en esos años como una herramienta coercitiva que afectó, entre otras cuestiones, a la militancia política (González Aleman, 2011; Caimari, 2012). Ello había sido posible a raíz del edicto del 16 de marzo de 1932 que, en los inicios del gobierno de Agustín P. Justo (1932-1938), puso en manos de la Policía de la Capital la reglamentación sobre las reuniones públicas al establecer la potestad de dicha institución para autorizar o no la realización de actos o manifestaciones en la vía pública. ${ }^{1} \mathrm{~A}$ finales de la misma década, el activismo político local existente como aquel promovido por las repercusiones de la Guerra Civil española y la Segunda Guerra Mundial, generaron que esta normativa sufriera diversas modificaciones. Los

\footnotetext{
${ }^{1}$ Como señaló González Aleman (2011) ello se inscribió en la "refundación" institucional pretendida por el nuevo gobierno, en busca de tomar distancia del "electoralismo" asociado al caudillismo yrigoyenista y al autoritarismo de la dictadura uriburista. Ver también "Una reglamentación democrática", en La Nación, año LXIII, nro. 21760, 18/03/1932, p. 4.
} 


\section{Construir un enemigo en tiempos de neutralidad: anticomunismo y disciplinamiento detrás de los debates por el derecho de reunión en Argentina (1938-1943)}

hechos represivos que promovieron las mencionadas discusiones parlamentarias en 1941 y 1942, en las que se exigió en tres oportunidades la interpelación al Ministro del Interior Miguel Culaciati, pusieron en evidencia una dinámica que, de acuerdo a las autoridades políticas y policiales, contemplaba la presencia del comunismo como un peligro para orden interno.

Concebimos como una primer hipótesis que las reformas aplicadas al edicto de 1932 fueron funcionales a la lógica anticomunista que guió y ordenó a la represión desde la llegada de Justo a la presidencia, y que apuntó contra distintas identidades políticas cuyas prácticas fueron englobadas dentro de la categoría de "actividades comunistas". El total de las herramientas de control ejercidas contra estas últimas, tanto por la Sección Especial del Represión al Comunismo (SERC) de la Policía de la Capital creada en abril de $1932^{2}$ como por otras instancias, tomó a las acciones, lineamientos y reivindicaciones del Partido Comunista argentino (PC) como una de sus bases para configurar un criterio de clasificación que intentó criminalizar a determinadas expresiones militantes, transcendiendo a la identidad comunista en términos partidarios. ${ }^{3}$ El resultado fue el desarrollo de una táctica de disciplinamiento en la que confluyeron representaciones y modalidades coercitivas elaboradas desde comienzos de siglo, tal es el caso de la figura del "agitador profesional" gestada en el contexto de la represión al anarquismo (Galeano \& Albornoz, 2017), que pone en evidencia cierto aprendizaje del Estado en esta materia. A su vez, durante los años que corresponden al análisis de este trabajo, la política de neutralidad adoptada por el gobierno argentino durante la Guerra Civil española (en ese caso, política de prescindencia) y la Segunda Guerra Mundial, habría también colaborado en el desarrollo de este tipo de represión, articulándose su cumplimiento con las disposiciones sobre las reuniones públicas y con algunas características asumidas por la militancia comunista en ese período. De esa manera, una segunda conjetura nos lleva a considerar que los mecanismos de disciplinamiento desplegados en esa coyuntura si bien fueron denunciados como un avasallamiento a las libertades individuales, apuntaron a constreñir determinadas expresiones políticas vinculadas al discurso anticomunista gestado en el transcurso de los años treinta.

Con estos objetivos, nos proponemos analizar a continuación el carácter asignado al peligro comunista en la configuración de medidas preventivas vinculadas a la prohibición o autorización de reuniones públicas, impulsadas por la Policía de la Capital y ejercidas por la SERC. Para ello evaluaremos distintos hechos represivos

\footnotetext{
${ }^{2}$ Si bien otros autores ubican su creación durante la dictadura de Uriburu (Rodríguez Molas, 1985; Kalmanowiecki, 1997; Camarero, 2007; Caimari, 2012; Iñigo Carrera, 2016), las Memorias de la Policía de la Capital y diversos documentos consultados respaldan la fecha que establecemos; ver "Al Señor Jefe de la División de Investigaciones", en Sección Especial, Memoria de Investigaciones. Policía de la Capital Federal, año 1932, 1ero de enero de 1933, p. 77.

3 La configuración de un criterio de clasificación y exclusión política en base a las ideas anticomunistas ha sido abordada para el caso chileno (Casals Araya, 2016). En relación a comprender al anticomunismo más allá de la identidad partidaria, pueden consultarse los trabajos de Patto Sá Motta (2000), Bohoslavsky y Vicente (2014), y Broquetas (2014).
} 


\section{Mercedes F. López Cantera}

comprendidos entre 1938 y 1943 y la justificación de las medidas de control dispuestas en esas ocasiones, siendo centrales para este estudio los edictos sobre reuniones y sobre asociaciones. Finalmente, incorporaremos los diversos debates que tuvieron lugar en el Congreso Nacional generados en torno a esas políticas, incluyendo las interpelaciones al Ministro del Interior Miguel Culaciati con motivo de las denuncias sobre represión.

\section{Represión y anticomunismo en los años treinta}

En el estudio de la represión de los años treinta es factible señalar su vinculación a una estrategia anticomunista ligada al desarrollo de un entramado represivo por la Policía de la Capital, dentro de lo cual la creación de la SERC se presentó como un pilar (Kalmanowiecki, 1997; López Cantera, 2014b). En el contexto del proceso de modernización de esa fuerza de seguridad impulsado durante la presidencia de Justo, el peligro rojo funcionó como el criterio que justificó la detención de numerosos militantes relacionados al movimiento obrero, brindando elementos que permitieron calificar a determinadas actividades como peligrosas para el orden social y político existente en el país. Este tipo de estrategias abarcaban desde tareas de vigilancia, control sobre la prensa, el empleo de edictos contravencionales y de leyes como la de Residencia (4144), incorporando al Poder Judicial como otro actor para limitar el desarrollo de ciertas prácticas. Los fallos contra Ángel Rosenblat, Angélica Mendoza y Lidia Lamarque, y el caso del periódico Bandera Roja, entre otros, como así el papel jugado por la Cámara Electoral que en 1928 estableció que el PC argentino no podía presentarse a elecciones por ser su estatuto contrario a la Constitución Nacional (fallo ratificado en 1930, 1932 y 1934), completaron la conformación del citado entramado. ${ }^{4}$ En paralelo, el entonces Ministro del Interior, el antipersonalista Leopoldo Melo, reconoció el funcionamiento de la SERC y lo justificó como parte de las estrategias preventivas que el Estado debía necesariamente emplear ante el desarrollo de las llamadas "actividades comunistas" y para combatir el "desviacionismo bandolero" que denunciaba presente en el movimiento obrero. ${ }^{5}$

A mediados de la década distintos factores incidieron en la continuidad de esta lógica represiva. La adopción del Frente Popular por el PC local fue interpretado por la Policía de la Capital como una estrategia de mayor peligrosidad en relación a la intransigencia de la línea de clase y contra clase (o "tercer período") adoptada entre

\footnotetext{
4 "Estadísticas y síntesis de delitos cometidos por comunistas. Años 1932 a 1934", en Mensaje contestando el pedido de informes acerca de las razones que determinaron la creación en la Policía de la "Sección especial de represión contra el comunismo", Archivo de la Cámara de Diputados, legajo nro. 115, 8 de agosto de 1934; "Desacato", en Jurisprudencia Criminal, Policía de la Capital-División Policial, tomo IV, 1934, pp. 171-173; Corte Suprema de Justicia de la Nación, "Anulación de Carta de Ciudadanía, 10 de agosto de 1934", en Jurisprudencia Criminal, Policía de la Capital-División Policial, tomo VI, 1934, pp. 175-201.

${ }^{5}$ Melo, Leopoldo, Mensaje contestando el pedido de informes acerca de las razones que determinaron la creación en la Policía de la "Sección especial de represión contra el comunismo", Archivo de la HCD, legajo nro. 115, 8 de agosto de 1934.
} 


\section{Construir un enemigo en tiempos de neutralidad: anticomunismo y disciplinamiento detrás de los debates por el derecho de reunión en Argentina (1938-1943)}

1928 y 1935: la preocupación radicó tanto en las posibles alianzas con otras fuerzas de izquierda como el Partido Socialista (PS), como en la potencial formación de un frente electoral que le permitiera a los comunistas locales llegar al poder del Estado. ${ }^{6}$ A su vez, la Policía alertó sobre esa situación dada también la fuerte presencia del PC en la dirección de importantes gremios obreros, preocupación que se profundizó una vez transcurridas las violentas jornadas de la huelga general del 7 y 8 de enero de 1936.7 Estas lecturas fueron compartidas por el mundo católico y por los nacionalistas, quienes observaron en las crisis políticas de los gobiernos frentepopulistas de Francia y España la confirmación del carácter destructivo y caótico que asignaban al comunismo (López Cantera, 2015 y 2018).

Corresponde subrayar que en ese marco el Estado profundizó la caracterización de numerosas entidades como "disfraces del comunismo". Desde comienzos del gobierno de Justo, la Sección Especial mantuvo un central interés en temáticas como la del antifascismo o el antimilitarimo a los que consideraba como banderas empleadas para cooptación de adeptos por parte de los comunistas. La estrategia de Frente Popular y las organizaciones vinculadas a la lucha antifascista (tanto las relacionadas al PC como la Federación de Organismos de Ayuda a la República Española - FOARE -, aquellas impulsadas por algunos militantes comunistas como la Asociación de Intelectuales Artistas Periodistas y Escritores -AIAPE-, y en algunos casos entidades ajenas, como Acción Argentina cercana al socialismo) fueron incluidas dentro de los intereses represivos de la SERC por considerarlas parte de la infiltración roja. ${ }^{8}$ En esa línea, el activismo en favor del bando republicano durante la Guerra Civil fue sospechado de jugar el mismo rol, posición denunciada por grupos católicos y nacionalistas que compartieron esta idea sobre los camouflages del peligro rojo, como por parte de la diplomacia argentina involucrada en la política de prescindencia asumida por los gobiernos de la Concordancia. Esto último respaldó los argumentos para la prohibición de diversos actos de ayuda pro-republicana (no así aquellos en favor del bando de "los Nacionales") acusados de violar la neutralidad adoptada. ${ }^{9}$

\footnotetext{
${ }^{6}$ La línea de clase contra clase impuso a partir de 1928 una política de intransigencia que anulaba todo tipo de alianzas de los partidos comunistas con otras fuerzas, impulsándose como modalidad de lucha las "huelgas revolucionarias". En octubre de 1935, el PC local la estrategia de Frente Popular que implicaba la organización de frentes antifascistas lo que incluía la alianza con fuerzas socialistas, socialdemócratas y liberales.

${ }^{7}$ Sobre la capacidad de expansión del comunismo con el Frente Popular: A S. E. el señor Ministro del Interior. Del Jefe de Policía, General de Brigada (S. R.) Andrés Sabalain, Memoria Correspondiente al año 1938, Policía de la Capital Federal, 31 de febrero de 1939, pp. 17-18. Sobre el PC y movimiento obrero entre 1930-1943: Camarero, Hernán, Comunismo y movimiento obrero en la Argentina, 19141946, (Buenos Aires: Facultad de Filosofía y Letras, UBA, 2008).

${ }^{8}$ A S. E. el señor Ministro del Interior. Del Jefe de Policía, General de División (R. A.) J. E. Vacarezza, Memoria Correspondiente al año 1937, Policía de la Capital Federal, 31 de enero de 1938, p. 14.

9 "Denuncias formuladas por la embajada de España", División Política. Ministerio de Relaciones Exteriores y de Culto, 07/05/1937, 26/04/1937, 19/10/1937, 11/08/1938, 12/08/1938, Caja 11, legajo 40, Archivo Guerra Civil Española - Archivo Histórico de la Cancillería Argentina.
} 
Durante el gobierno de Roberto M. Ortiz estas cuestiones convergieron en las problemáticas que atravesaron al ciclo. En junio de 1938 el Jefe de la Policía de la Capital, Andrés Sabalain, presentó al Ministerio del Interior un proyecto de reforma del edicto sobre reuniones públicas de 1932 con motivo de los enfrentamientos consecuentes al acto nazi celebrado en abril de 1938 en el Luna Park (Newton, 1995:230-233; Romero, 1998). La propuesta no hizo referencia únicamente a ese caso: en la misiva también se apuntó a la "agitada vida política" afectada por las repercusiones de los sucesos europeos y por el antagonismo entre extranjeros que "no pueden sustraerse a los distintos intereses que se ventilan en su país". ${ }^{10}$ Sabalain señaló que las campañas de solidaridad evidenciaban que las entidades comprometidas solo buscaban "conquistar adeptos", cuestión además agravada por la "infiltración de agitadores de ideas avanzadas" en busca de perturbar el orden. En suma, dicho escenario fundamentaba el incremento del control sobre el espacio público, capacidad que el Jefe de Policía consideró "facultativa" de la institución. ${ }^{11}$ Esta última disposición no fue considerada y recién el 15 de mayo de 1939 el Poder Ejecutivo emitió un decreto reglamentario de asociaciones con el que se prohibió el uso o tenencia de distintivos ajenos a los del Estado argentino, o todo acto relativo a asuntos políticos o de solidaridad con países extranjeros. ${ }^{12} \mathrm{Si}$ bien el principal objetivo de ello era limitar las acciones ligadas a los países del Eje, aquellas relacionadas a la lucha contra el fascismo podían verse alcanzadas por esta disposición. En ese contexto, contemplando la asociación entre antifascismo y comunismo, considerando que las campañas en favor de los refugiados del bando republicano español continuaban su marcha, y teniendo en cuenta que el PC aún no había adoptado la política de neutralidad que sostendría entre agosto de ese año hasta mediados de 1941, producto del pacto Ribbentrop-Molotov (Piro Mittelman, 2018), ¿qué podría suceder con las llamadas "actividades comunistas"? ¿La Policía de la Capital reparó en ello a la hora de lanzar sus disposiciones sobre el espacio público? Para comprender la afinidad entre dichas herramientas y la lógica represiva anticomunista analizaremos a continuación las discusiones generadas en torno al derecho de reunión y las posiciones del gobierno de Ramón Castillo.

\section{Anticomunismo en los debates por el derecho de reunión}

\footnotetext{
${ }^{10}$ A S. E. el señor Ministro del Interior. Del Jefe de Policía, General de Brigada (S. R.) Andrés Sabalain, $1^{\circ}$ de junio de 1938, en Memoria Correspondiente al año 1938, Policía de la Capital Federal, pp. 55-57. Sobre el acto en el Luna Park: "Como acto de adhesión al Gran Reich se congrego en el Luna Park la colectividad Germano-Austriaca" y "Al margen de un acto de la Federación Universitaria produjeronse incidentes", en La Nación, año LXIX, nro. 23964, 11 de abril de 1938, pp. 9 y 10.

${ }^{11}$ A S. E. el señor Ministro del Interior. Del Jefe de Policía, General de Brigada (S. R.) Andrés Sabalain, $1^{\circ}$ de junio de 1938, en Memoria Correspondiente al año 1938, Policía de la Capital Federal, p. 56.

${ }^{12}$ Poder Ejecutivo, Decreto reglamentario de asociaciones, 15 de mayo de 1939. Ello fue disparado a raíz del llamado "escándalo de la Patagonia" cuando se dio a conocer la denuncia de un supuesto plan de invasión nazi en esa región (Friedman, 2010:91-92; Newton, 1995:240-258).
} 


\section{Construir un enemigo en tiempos de neutralidad: anticomunismo y disciplinamiento detrás de los debates por el derecho de reunión en Argentina (1938-1943)}

En 1940 las reuniones públicas volvieron a ser objeto de preocupación. En octubre del mismo año la Policía emitió un nuevo edicto entendido como una ampliación del de 1932, que establecía la prohibición de todo evento cuyo contenido atentara o al "orden interno, a la paz social y a la tranquilidad pública del país", o fuera contrario a las relaciones amistosas que la Nación mantuviera con otros países, todo ello contemplado en los subincisos 2, 3 y 4 del inciso b), del artículo $1^{\circ}$. De acuerdo a comunicaciones internas, el Ministro Culaciati y el aún Jefe de Policía Sabalain, coincidieron en definir a las actividades de solidaridad internacional como factor de conflicto. ${ }^{13}$ Como señala Bisso (2005:175-176), la prohibición de esos eventos fue justificada en general por razones formales; sin embargo, esas explicaciones de tipo operativas podían encerrar también la vinculación con la acusación de infiltración "roja". Ello puede verse reflejado en 1941 cuando, en referencia a la militancia comunista, la Policía de la Capital subrayó la agitación promovida por las acciones tanto en defensa de la neutralidad durante los primeros meses como las posteriores a favor de la intervención. ${ }^{14}$ Para la fuerza de seguridad ello era comparable con el marco vivido durante la contienda española; al respecto, el nuevo Jefe de Policía, Juan C. Rosas, informaba:

"Al Partido Comunista, que se presenta en sus pedidos bajo distintos nombres de asociaciones estudiantiles, sociales, obreras e intelectuales, se le han prohibido reuniones públicas para evitar la difusión de ideas contrarias a nuestra Constitución (...) Y aún más, señor Ministro, bajo el amparo del Partido Radical, diversas entidades de fisonomía netamente comunista han pretendido celebrar reuniones públicas como la que se prohibió con fecha el 17 de enero ppdo., en el Cinematógrafo de la calle Corrientes 5424, circunstancia que dió lugar a la presentación a la comisaría seccional del diputado Arbeletche para formular un reclamo."15

En esa misiva se mencionaban otras prohibiciones, como las ejercidas contra reuniones de la UCR, aunque es de destacar la directa identificación de todo evento organizado por cualquiera de las entidades vinculadas directa o indirectamente al PC con ideas "contrarias a la Constitución". Atentar contra el orden constitucional era el criterio que definía la desautorización de esos eventos. El comunismo aparecía en estos documentos como sinónimo de "atentado contra el orden interno", alcanzando a organizaciones en solidaridad con los conflictos bélicos del exterior en

\footnotetext{
13 Culaciati, Miguel, Al señor Jefe de Policía de la Capital, 9 de octubre de 1940, 38 Sesión ordinaria, 49 Reunión, Honorable Cámara de Diputados de la Nación, 17 de septiembre de 1941; Edicto sobre reuniones públicas (ampliatorio), Policía de la Capital, Ministerio del Interior, 19 de octubre de 1940. ${ }^{14}$ A S. E. el señor Ministro del Interior. Del Jefe de Policía, General de Brigada Domingo Martínez, 31 de marzo de 1942, Memoria Correspondiente al año 1941, Policía de la Capital Federal, 14-15. Asimismo, las autoridades señalaban "una mayor calma en los conflictos obreros".

${ }^{15}$ A S. E. el señor Ministro del Interior. Del Jefe de Policía, Capitán de Navío (R.) Juan C. Rosas, 14 de febrero de 1941, Memoria Correspondiente al año 1941, Policía de la Capital Federal, 70-72. Esta misiva se hallaba vinculada al intercambio entre ambas autoridades con motivo de un pedido de informes realizado por la Liga Argentina por los Derechos del Hombre (LADH) en la Cámara de Diputados. $L A D H$, solicita que se requieran informes sobre el ejercicio del derecho de reunión en la Capital Federal, Honorable Cámara de Diputados de la Nación, $17^{\circ}$ Sesión extraordinaria, $73^{\circ}$ reunión, 12 de febrero de 1941, 150.
} 


\section{Mercedes F. López Cantera}

tanto su carácter de "disfraz", acusadas de violar la neutralidad establecida por el gobierno.

Días después de esta comunicación, varios militantes en su mayoría miembros del PC, fueron detenidos por agentes policiales. Durante la noche del 5 de marzo la policía privó de su libertad a Pedro Chiarante, Luis Fiore, Pedro Tadioli, Angel Molesini, Miguel Burgas, Andrés Roca, José Vidan, Víctor Larralde, Roque Alsace, Pablo Mailing y Alfredo Bonini, todos ellos del Sindicato Único de la Construcción (SUOC) en el local ubicado en la calle Victoria 2936. Al día siguiente, en medio de las negociaciones establecidas por una comisión obrera con el diputado Aníbal Arbeletche - presidente del Comité de Capital Federal de la UCR - para que éste intercediera ante las autoridades, fueron detenidos Francisco Cuenca y Dionisio Pellicero, trabajadores textiles, Vicente Michelon - Secretario General de la Unión Obrera Textil -, José Peter (dirigente del Sindicato Obrero de la Alimentación) y Orlando Amieva, vinculado a organización Acción por los Derechos de la Juventud. Además, a las 18hs. del mismo día la policía allanó al Sindicato Obrero Metalúrgico, secuestrando diversos materiales. Tras ser liberados en la mañana del 8 de marzo, todos los afectados decidieron reunirse en la puerta del local de la calle Victoria y al no contar con autorización para justificar ese encuentro público, fueron nuevamente detenidos. ${ }^{16}$

Inicialmente, la Policía de la Capital explicó a la prensa que el motivo había sido la averiguación de antecedentes. A su vez, a pesar que el procedimiento del día 6 se había realizado de la mano de la Sección de Orden Social, el destino de los detenidos fue la comisaría $8^{\circ}$ de Urquiza al 500, sede de la SERC. De acuerdo a testimonios que luego fueron reproducidos por diputados, los familiares de los militantes al presentar sus amparos a las autoridades de esa comisaría, éstas explicaron que los sujetos no se encontraban allí sino en el Departamento Central de Policía, donde funcionaba la segunda de las tres ubicaciones de la SERC (la tercera era el Cuadro X de la cárcel de Devoto). Cuando los querellantes se dirigieron a este último obtuvieron una respuesta similar: que tampoco podían reclamar ya que los detenidos habían sido trasladados nuevamente a Urquiza al 500. No obstante, esta situación no constituyó un caso aislado. En octubre de 1939 un grupo de militantes del PC había sido detenido en sus domicilios sin orden judicial y conducidos a la comisaría de la calle Urquiza. Uno de ellos, Abraham Pergament, como castigo a su mala conducta, fue reenviado a la comisaría de la localidad de Avellaneda; dado que los agentes responsables de dicha dependencia no habían ingresado los datos de su persona en los libros correspondientes, la familia no pudo exigir el pedido de habeas corpus en esa dirección mientras que dejaba sin efecto aquél asentado en la comisaría $8^{\circ} \cdot{ }^{17}$ Este tipo de movimientos de una dependencia a otra de la Sección Especial imposibilitaban asentar los recursos de amparo. Si al menos en dos

\footnotetext{
16 "La situación política volverá a ser considerada en el Congreso", en La Prensa, año LXXII, nro. 25931, 9 de marzo de 1941, 12.

17 "Protestan por el malón policial” y “Secuestro de libretas de enrolamiento, torturas y 'picana' eléctrica en la Sección Especial”, en Orientación, año III, 5 de octubre de 1939, 1 y 5-6.
} 


\section{Construir un enemigo en tiempos de neutralidad: anticomunismo y disciplinamiento detrás de los debates por el derecho de reunión en Argentina (1938-1943)}

oportunidades la SERC actuó de la misma manera, ¿debemos suponer que era una práctica intencionada de la Policía de la Capital para evadir la "ayuda jurídica"?18

Como resultado de la incertidumbre provocada por la institución policial, el día 7 el diputado nacional de la UCR por la provincia de Córdoba, Reginaldo Manubens Calvet, y el socialista por la Capital Federal, Julio V. González, elevaron durante el período de sesiones extraordinarias un pedido de interpelación a Miguel Culaciati para el 12 de marzo. Manubens Calvet centró su moción en el accionar de la Policía de la Capital a la que responsabilizó de crear "un ambiente de terror que cunde ya en los gremios obreros, en algunos partidos políticos y he de decir cómo se ha constituido en el órgano perseguidor de todos aquellos ciudadanos que tienen en la República una confesada posición liberal." ${ }^{19}$ Las cifras con las que el diputado cordobés acompañó su posición señalaban los siguientes detenidos: 115 pertenecientes a la Acción por los Derechos de la Juventud durante septiembre de 1940, 74 que asistían al Congreso de la Juventud (17 mujeres entre éstos) el día 4 de febrero de 1941, y en los días previos a la sesión en curso unos 17 hombres por "vivar" al presidente Ortiz; a ello sumó la denuncia realizada por familiares sobre los impedimentos para asentar los distintos habeas corpus mencionados. ${ }^{20}$ Vale hacer referencia a la inserción por el diputado González de un documento redactado por el SUOC y firmado por Rubens Íscaro, dirigente comunista de la construcción. Centrado en la descripción de los sucesos de los días 5, 6 y 7 de marzo, el anexo sintetizaba las distintas exigencias que el sindicato de la construcción estaba padeciendo: el pedido con 5 días de anticipación para llevar a cabo reuniones, la vigilancia permanente por tres agentes en la puerta de su local, la prohibición de mantener abierto al mismo más allá de las 19:30hs., y otras dos limitaciones, una para realizar actos públicos y otra para inaugurar nuevas seccionales del gremio.21 A pesar que el proyecto de interpelación fue aprobado, el ministro Culaciati no se presentó. En su lugar envió un informe donde señalaba que en el último año había tenido lugar un "recrudecimiento de las actividades comunistas".22 De acuerdo a ello

\footnotetext{
18 En 1934 el Ministro Melo explicó en su informe sobre la SERC que el comunismo había introducido una nueva estrategia para promover la agitación interna: el asesoramiento legal por parte de abogados y entidades como el Socorro Rojo Internacional (López Cantera, 2014b). Ver "Sección especial", en Mensaje contestando el pedido de informes..., folios 80 y 81.

19 Moción del diputado Manubens Calvet para considerar sobre tablas los proyectos subscriptos por el mismo señor diputado como por otros, y por el señor diputado González, solicitando informes al Poder Ejecutivo por la detención de dirigentes obreros, políticos y estudiantes, en $79^{\circ}$ reunión $23^{\circ}$ Sesión Extraordinaria, 7 de marzo de 1941, HCDN, 487-499. Ver también "La comisión especial del senado se reunirá esta tarde nuevamente. La sesión de mañana en la cámara de Diputados”, en La Prensa, año LXXII, nro. 25933, 11 de marzo de 1941, p. 12.

20 Moción del diputado Manubens Calvet para considerar sobre tablas..., 487-488.

21 Inserción solicitada por el diputado González. Señor Presidente del bloque parlamentario, Buenos Aires 10 de marzo de 1941, en Se considera la interpelación del ministro del Interior ..., 631-632.

22 "Mensaje del Ministro del Interior a la Honorable Cámara de Diputados de la Nación”, en Moción del diputado Manubens Calvet, para entregar a los señores diputados una copia de los informes del ministro del Interior, relacionada con la detención de dirigentes políticos y obreros, y de fijar mañana para tratar, como primer asunto, la interpelación sobre esta cuestión. Es aprobada. $80^{\circ}$ reunión $24^{\circ}$ sesión extraordinaria, 12 de marzo de 1941, HCDN, 530-536.
} 


\section{Mercedes F. López Cantera}

y a la función que asignaba a la Policía de la Capital, la de vigilar a aquellos grupos o personas "que constituyan fermentos peligrosos de disolución social", el ministro consideraba que esa institución se encontraba habilitada para llevar adelante tareas de averiguación de antecedentes de miembros del movimiento obrero y político a fin de actualizarlos e informar sobre sus "medios de vida". Esto último hacía referencia a la figura del "agitador profesional", por la que la Policía intentaba justificar la detención de dirigentes obreros y/o políticos alegando que los mismos no eran trabajadores insertos en el rubro que decían representar, poniendo en duda el origen de su sostén económico.

El informe constataba que las detenciones no tenían que ver con el "auténtico movimiento obrero argentino" sino con aquellas figuras que ponían en peligro a la estabilidad constitucional, posición similar a la expresada por Leopoldo Melo en 1934, y que el accionar policial era un medio para evitar que el movimiento obrero se convirtiese en un instrumento de "dictaduras de izquierda y de derecha". 23 De esa manera, rescataba el papel de la Unión Ferroviaria y de la CGT como "verdaderas organizaciones de los obreros" que habían denunciado perturbaciones en sus gremios provocadas por los "sindicatos comunistas", a los que consideraba insignificantes en número y responsables de la presencia de agitadores. Para justificar estas posiciones, el documento detallaba distintos ejemplos de la infiltración roja en el país, partiendo del análisis de los estatutos de la III $^{\circ}$ Internacional hasta citas que demostraban la manifiesta voluntad de crear organizaciones clandestinas o penetrar en partidos políticos y otras entidades a través del Frente Popular. Finalmente, la mirada del Poder Ejecutivo en 1941 frente a la cuestión comunista se sintetizó en el objetivo de reforzar el "poder de policía" del Estado, es decir, reducir - entre otras cuestiones - al derecho de reunión "a sus menores límites", con el fin de sostener y recrudecer la vigilancia sobre "la penetración de los comunistas en los partidos políticos y las organizaciones obreras.".24

En este marco, a fines de julio de 1941 un nuevo edicto fue emitido. Éste, contemplando la presentación de un proyecto de ley sobre el derecho de reunión, dejaba sin efecto aquellos edictos de 1932 y 1940, volviendo a establecer la autoridad de la Policía de la Capital para habilitar las reuniones públicas, e incorporaba las siguientes disposiciones: la autorización en el artículo $4^{\circ}$ para todo evento organizado sea por partidos políticos con personería, o para actividades religiosas o para "actos patrióticos", y que las reuniones con fines gremiales debían llevarse a cabo en un local cerrado (artículo $5^{\circ}$ ).25 A comienzos de septiembre el Ministro del Interior envió una nota al Jefe de Policía solicitando reforzar las

\footnotetext{
23 "Mensaje del Ministro del Interior a la Honorable Cámara de Diputados de la Nación”, en Moción del diputado Manubens Calvet, para entregar a los señores diputados..., p. 532.

24 "Mensaje del Ministro del Interior a la Honorable Cámara de Diputados de la Nación”, en Moción del diputado Manubens Calvet, para entregar a los señores diputados..., pp. 534-535.

25“"Reuniones públicas. Disposición 857”, 25 de julio de 1941, en Disposiciones de Policía. (Ministerio del Interior, Policía de la Capital), 434-439.
} 


\section{Construir un enemigo en tiempos de neutralidad: anticomunismo y disciplinamiento detrás de los debates por el derecho de reunión en Argentina (1938-1943)}

medidas de la nueva normativa y de los decretos sobre funcionamiento de asociaciones en favor de evitar todo tipo de propaganda "antidemocrática", por la que se agraviara a los funcionarios públicos y/o se incite “... a la modificación violenta de las instituciones políticas y sociales del país...” para lo cual exigía una "rigurosa vigilancia" en asociaciones, clubs, bibliotecas y comités, entre otros. ${ }^{26}$

El "refuerzo" solicitado por el Ministro del Interior dio por resultado una serie de allanamientos contra entidades vinculadas a la solidaridad internacional que motivaron un segundo pedido de interpelación por la Cámara de Diputados para fines de agosto de 1941. Aquí podemos mencionar algunas de las denuncias enviadas a la Comisión Especial de Investigaciones de Actividades Antiargentinas (CEIAA), como el caso de la Unión Democrática de Ayuda a los Pueblos Soviéticos, Inglés y Demás Agredidos por el Nazi-fascismo. A pesar de haber presentado al Ministerio del Interior la información y requisitos solicitados para actuar como entidad, el 23 de agosto fue allanado su local por la SERC sin orden judicial y secuestrados distintos materiales a la venta destinados como fondo de ayuda, al tiempo que todos los presentes fueron enviados a la comisaría $8^{\circ}$ acusados de violar el edicto de reuniones públicas. ${ }^{27}$ Varias reuniones o actividades de la FOARE (como la conmemoración de la fundación de la República española el 18 de abril de 1941, o un festival a beneficio de refugiados españoles del 31 de mayo) fueron interrumpidas con varios detenidos como saldo. ${ }^{28}$

El nuevo pedido de interpelación tampoco fue respondido con la presencia del ministro, por el contrario éste envió a la Cámara de Diputados una nómina de 144 entidades cuyas actividades fueron afectadas por las regulaciones sobre el espacio público. ${ }^{29}$ El documento insertado en la sesión del 17 de diciembre incluyó aquellas reuniones cuya autorización había sido denegada, exponiendo los motivos de cada una de las prohibiciones. Sobre el total, 55 de esas prohibiciones se radicaban en el incumplimiento de los subincisos 2 y 4 del artículo 1 inciso b) del edicto del 19 de octubre de 1940 de los que hemos hecho referencia anteriormente; por otra parte, 33 casos se vinculaban al incumplimiento del decreto sobre asociaciones que prohibía la interferencia en asuntos de naciones extranjeras. Aquellas cuestiones vinculadas al carácter comunista, sea por la identidad de la organización, sus oradores o sus temáticas, fueron solamente 14.

\footnotetext{
26 Culaciati, Miguel, Al Sr. Jefe de Policía de la Capital, 1ero. de septiembre de 1941. Memoria Correspondiente al año 1941, Policía de la Capital Federal, 128-129.

27 Unión Democrática de Ayuda a los Pueblos Soviéticos, Inglés y demás agredidos por el nazifascismo, Al Sr. Diputado, 5 de septiembre de 1941, en CEIAA, Comisiones Especiales, Archivo del Patrimonio y Memoria de la Honorable Cámara de Diputados de la Nación (apym.hcdn.gob.ar). Asimismo, dos miembros de esa organización al presentarse ante las autoridades policiales para exigir la liberación de los afectados fueron detenidos.

${ }^{28}$ FOARE, Al Sr. Presidente de la CIEAA, Dr. Damonte Taborda, 12 de septiembre de 1941, en CEIAA, Comisiones Especiales, Archivo del Patrimonio y Memoria de la Honorable Cámara de Diputados de la Nación (apym.hcdn.gob.ar).

${ }^{29}$ Se invita al Ministro Culaciati a ser interpelado para el 17 de septiembre sobre el derecho de reunión, $30^{\circ}$ Sesión ordinaria, $36^{\circ}$ reunión, Honorable Cámara de Diputados de la Nación, 28 de agosto de 1941.
} 
Al observar los afectados por los mencionados subincisos del edicto de 1940 encontramos, en primer lugar, organizaciones gremiales y, en segundo, a aquellas acusadas de ser "disfraces" del comunismo. Corresponde preguntarnos nuevamente sobre el criterio empleado por la Policía. Contemplando que un par de asociaciones como el Partido Socialista Obrero fueron catalogadas como "comunistas" (incluyendo a la Federación Obrera Regional Argentina), ¿qué determinó que aquellas relacionadas a esa línea política como la FOARE o el semanario del PC Orientación fueran contempladas bajo esos subincisos y no clasificadas como "comunistas"? De acuerdo a lo analizado hasta este punto, la Policía había asumido la caracterización de ese tipo de entidades como caballos de Troya del peligro rojo. Ahora, las mismas eran englobadas en aquellos delitos o actos concebidos como contrarios al orden social y político.

Estos interrogantes pueden volver a formularse en otra coyuntura acaecida en esos años. El 16 de diciembre de 1941 tras la llegada de las noticias del bombardeo japonés a Pearl Harbour, el Poder Ejecutivo en manos de Ramón Castillo decretó el Estado de Sitio. Las acciones represivas impartidas en ese contexto y el debate sobre la atribución del Poder Ejecutivo para aplicar el artículo 23 de la Constitución Nacional durante el receso del Poder Legislativo fueron las razones que llevaron a otro pedido de interpelación a Culaciati, quien finalmente accedió a presentarse en la Cámara de Diputados el 24 de junio de $1942 .{ }^{30}$ Durante la sesión, el Ministro hizo referencia a la problemática del peligro comunista en la Argentina como la principal justificación de dicha escalada represiva, intentando calificarlo como "actividad antiargentina". Para ello recurrió a investigaciones realizadas tanto por su ministerio y como por la CEIAA con el objetivo de defender el carácter preventivo del Estado de Sitio y la necesidad de su aplicación para proteger al "común ideal democrático".

Uno de los antecedentes más relevantes que Culaciati empleó para validar la calificación del comunismo como enemigo del orden interno fue el fallo de la Corte Suprema de Justicia de la Nación del 10 de diciembre de 1941. El mismo confirmaba la sentencia dictada por un juzgado correccional que había establecido la constitucionalidad del edicto de 1940 ante la apelación realizada por el representante de María Elena Álvarez de Shuster. Ésta había sido detenida junto a diez personas en una casa sita en Cangallo 1556 el 24 de junio de ese año "por hallarse reunidas sin autorización policial en dicho lugar, donde funcionaba una biblioteca pública del partido comunista." ${ }^{31}$ La apelación quiso objetar la inconstitucionalidad del edicto y cuestionar la facultad de la Policía para el dictado de ese tipo de recurso legal sin éxito.

\footnotetext{
${ }^{30}$ El debate respecto a la declaración del Estado de Sitio incluyó la presentación de un proyecto de Ley de Resolución para establecer nuevas disposiciones en la declaración del Estado de Sitio presentado por Carlos Sánchez Viamonte. Finalmente el Congreso lo ratificó y el mencionado proyecto pasó a una segunda revisión a la Comisión de Asuntos Constitucionales. HCDN, 14a. Reunión 12a. Sesión Ordinaria, 1ero. de Julio de 1942; HCDN, 29a. Reunión 27a. Sesión Ordinaria, 11 de agosto de 1942; HCDN, 29a. Reunión 27a. Sesión Ordinaria, 11 de agosto de 1942.

31"Amador Spagnol, María Elena Álvarez de Shuster y Otros", Buenos Aires, 10 de diciembre de 1941. Fallos de la Corte Suprema de Justicia de la Nación, Tomo 191, 1941, 388-400.
} 
Construir un enemigo en tiempos de neutralidad: anticomunismo y disciplinamiento detrás de los debates por el derecho de reunión en Argentina (1938-1943)

En primer lugar, los fundamentos del fallo de la Corte señalaban que las reuniones autorizadas debían revestir carácter legal y explicaban que la actividad desarrollada en la pieza de Cangallo al 1500 no cumplía con ese requisito dado que la misma respondía a contenidos contrarios a la constitución. De acuerdo al artículo 29 de la Carta Magna todo acto que llamara a suplantar el régimen establecido por la máxima ley debía considerarse como un acto de traición a la Patria y dado que la actividad interrumpida era de un partido político que respondía, además, a directivas extranjeras de la URSS, la misma era considerada contraria al orden establecido. De acuerdo al tribunal supremo, esa reunión constituía un peligro ya que las temáticas y discusiones que estaba llevando a cabo no respondían a un intercambio de ideas que podía realizarse en cualquier encuentro privado, sino a un programa de acción concreto funcional a intereses extranjeros tal como lo demostraba la organización del PC. Esto último fue respaldado por otros hechos precedentes considerados por la Corte: los argumentos del ex senador Matías Sánchez Sorondo que habían validado la media sanción de la Ley de Represión al Comunismo por parte del Senado en 1936 (López Cantera, 2014a), y el fallo que permitió el desafuero de Enrique Del Valle Iberlucea de 1921. En suma, la conclusión determinaba el carácter ilícito e ilegal de la reunión por sus contenidos específicos, no por el encuentro en sí mismo, y por lo tanto ratificaba la facultad del Jefe de Policía para disolver actividades de esas características.

En su justificación al Estado de Sitio basada en la alerta comunista, Culaciati invocó, en segundo lugar, a las resoluciones de la Conferencia de Río de Janeiro de enero de 1942. En ella, si bien la delegación argentina defendió la adopción de la neutralidad frente a las presiones de EEUU, se reafirmó la voluntad de las naciones firmantes de impedir por medio de toda herramienta legislativa acciones o propaganda afines a poner en peligro a las instituciones democráticas (Morgenfeld, 2011:257-264 y 290314; Potash, 1981:238-246). De esa manera explicó que las causas por las que debía dar cuenta al senado se encontraban englobadas en la aplicación del estado de excepción para frenar la presencia de movimientos ideológicos o "fenómenos de penetración" que atentaran o fueran perjuicio del orden democrático. Esas mismas causas se encontraban vinculadas de acuerdo a Culaciati a "actividades comunistas", definidas como ilícitas y correspondientes a una ideología "contraria a la propiedad, al hogar y a la libertad individual", cuya peligrosidad para la Argentina radicaba además en el desarrollo de las mismas a lo largo y ancho del territorio: “... están en las escuelas, en los movimientos gremiales, en las universidades. Han invadido toda la República.....32

Finalmente, el ministro citó un documento perteneciente al Comité de Actividades Antinorteamericanas de los EEUU en el que se daba cuenta de las llamadas "organizaciones de frente": asociaciones gestadas por simpatizantes del partido comunista local que sumaban adeptos bajo convocatorias democráticas y ejecutaban

${ }^{32}$ Se considera la interpelación al señor ministro del Interior, relacionada con el Estado de Sitio ..., $172-$ 173. 
así planes funcionales a los intereses rojos. ${ }^{33}$ Así, ratificó el mencionado fallo de la Corte por validar a los edictos policiales sobre reuniones públicas ya que a través de ellos el gobierno buscó "evitar la proliferación de reuniones" durante el Estado de Sitio que, detrás del "engendro enorme de la actividad ideológica", escondían actividades antidemocráticas. En consecuencia, enumeró un conjunto de asociaciones - tanto pertenecientes al PC como la Federación Juvenil Comunista, hasta otras cuyos miembros podían pertenecer o no al mismo, como la AIAPE o la Organización Popular contra el Racismo y el Antisemitismo - a las que acusó de aprovecharse de "demócratas ingenuos" para fomentar la infiltración disolvente. La participación de figuras ajenas a la identidad comunista partidaria en algunas de las organizaciones mencionadas (Bisso, 2005:176) no disuadió al Ministro de dicho calificativo. En definitiva eran aquellas temáticas cuya peligrosidad había sido definida a lo largo de los años treinta, lo que determinaba esa calificación.

Las reformas al edicto de 1932 que hemos analizado dan muestra de la discusión existente sobre el carácter que debía revestir una reunión pública autorizada, lo que significó establecer qué actividades y componentes debían ser discriminados. El análisis de la comunicación entre el Ministerio del Interior y la Jefatura de Policía demuestran que esa valoración encerró un contenido ideológico preciso que implicó la consideración de las llamadas "actividades comunistas" en tanto peligrosas para el orden político del país, consolidándose así lo que Casals Araya (2016) denominó como "criterio de exclusión" a partir del anticomunismo desplegado por esa fuerza de seguridad desde comienzos de los treinta. En este punto, las acciones de solidaridad internacional emprendidas en el contexto de los enfrentamientos de esos años fueron clasificadas como perturbaciones para el orden interno, lo que significó el encuentro de dos cuestiones. Por un lado, la concepción de banderas como la del antifascismo en tanto disfraces del comunismo, por otro, el incumplimiento de la política de prescindencia (caso Guerra Civil) y de neutralidad establecida luego de 1939. Ambos factores condujeron a limitar manifestaciones políticas impulsadas por entidades vinculadas al PC como a otras identidades políticas a las que alcanzaba la calificación de peligrosidad.

Aquí corresponde señalar que la caracterización general de expresiones como la militancia antifascista en tanto sinónimo de comunista podría apoyarse en la

\footnotetext{
${ }^{33} \mathrm{El}$ informe citado era una investigación realizada entre 1939 y 1940 por el diputado por Alabama Joe Starnes (era representante demócrata y defensor de las leyes de segregación existentes en los estados sureños) por el que se denunciaban las organizaciones satélites del comunismo, la mayoría de ellas vinculadas a la lucha antifascista, el movimiento pro refugiados españoles y las entidades contra el racismo y defensa de los derechos de los afroamericanos. Se considera la interpelación al señor ministro del Interior..., 178-179.
} 


\section{Construir un enemigo en tiempos de neutralidad: anticomunismo y disciplinamiento detrás de los debates por el derecho de reunión en Argentina (1938-1943)}

vinculación del activismo del PC con ese tipo de banderas, pero su impugnación reposó finalmente en ser consideradas compromisos políticos ajenos a "los intereses nacionales". Este rechazo se encontró en la misma línea que el desplegado contra reclamos que eran considerados ilegítimos de acuerdo a los procedimientos de la Policía de la Capital: la descalificación de las huelgas generales o en solidaridad como "políticas", o el compromiso del movimiento sindical contra la lucha antirepresiva interpretado en tanto una desviación de las "verdaderas" reivindicaciones obreras. La ajenidad del antifascismo no respondía solamente a su compromiso con naciones extranjeras o luchas foráneas, sino que ello sintetizaba la clasificación y el criterio que el Estado venía elaborando sobre qué autorizar y qué no, posición compartida por otros actores "defensores del orden" como los mencionados católicos y nacionalistas. Ello encerraba, por otra parte, el comportamiento que el Estado esperaba de la clase obrera, a nivel de sus reivindicaciones como de sus organizaciones políticas.

En segundo lugar, es importante señalar que el desarrollo de ese criterio quedó en manos de la Policía de la Capital. Continuando con la línea señalada por otros autores, esa fuerza de seguridad fue la encargada de definir lo relativo no sólo al derecho de reunión sino también a la regulación de asociaciones. En este punto, el entramado represivo desarrollado desde comienzos del gobierno de Agustín P. Justo empalmó con estas tareas de definición, tal como lo señalan el replanteo sobre el control de reuniones públicas a partir de las reformas y propuestas llevadas a cabo durante la gestión de Diógenes Taboada como Ministro del Interior de Ortiz y luego con Miguel Culaciati. La superioridad del edicto policial por sobre toda regulación que fuera tramitada por los poderes políticos ya había sido reafirmada en el informe Melo de 1934 y a lo largo de esos años por la propia institución, lo que avalaba la potestad de esa fuerza sobre el activismo llevado a cabo en la esfera pública.34

Estas prácticas y los fundamentos brindados por las diversas autoridades citadas en este trabajo, nos señalan que para comienzos de los años cuarenta el Estado argentino asumía su carácter "de policía" (en palabras de Culaciati) y que ello respondía a connotaciones políticas específicas. En 1941, el citado fallo de la Corte Suprema puso en evidencia que el criterio de clasificación y/o exclusión no buscaba avanzar sobre las libertades civiles en términos generales sino sobre determinadas expresiones. Fue el carácter comunista de las reuniones allanadas o suspendidas lo que sentenció su prohibición. No obstante la defensa de la democracia expresada por la línea frentepopulista de los partidos comunistas del período, el comunismo continuaba siendo homologado a una ideología disolvente o un proyecto revolucionario, de la misma manera que aquellos reclamos "ajenos" a la coyuntura nacional eran comprendidos como un desprendimiento de ello o un vector que podía conducir a posiciones disruptivas del orden nacional. Tal como demostró el informe

\footnotetext{
34Díaz, Antonio. “Derecho de reunión”. Revista de Policía y Criminalística de Buenos Aires. Policía de la Capital Federal, tomo III, nro. 17, tomo IV (1939): 9-12; Díaz, Antonio. “Derecho de reunión”. Revista de Policía y Criminalística de Buenos Aires. Policía de la Capital Federal, nro. 18, (1940): 17-18.
} 


\section{Mercedes F. López Cantera}

sobre las reuniones prohibidas de agosto de 1941, la categoría "comunista" terminó siendo un argumento pocas veces empleado, prefiriendo encasillar a militantes y organizaciones sospechosas (en su mayoría pertenecientes a esa identidad) como un peligro para el orden interno, este último identificado por las autoridades como democracia. En las vísperas del golpe de Estado de 1943 y todavía faltando un par de años para el desenlace de la Segunda Guerra Mundial y el comienzo de la Guerra Fría, el Estado argentino daba nombre a quien consideraba enemigo de los valores democráticos y de la paz interior.

\section{Bibliografía}

Bisso, Andrés (2005). Acción Argentina. Un antifascismo nacional en tiempos de Guerra Mundial. Buenos Aires: Prometeo.

Bohoslavsky, Ernesto (2010). Las derechas en Argentina, Brasil y Chile (19451959): una propuesta comparativa. Revista de Historia Comparada (4-2).

Bohoslavsky, Ernesto y Vicente, Martín (2014). 'Sino el espanto'. Temas, prácticas y alianzas de los anticomunismos de derecha en Argentina entre 1955 y 1966. Anuario del Instituto de Historia Argentina (14).

Bohoslavsky, Ernesto y Bertonha, João Fábio, (comps) (2016). Circule por la derecha. Percepciones, redes y contactos entre las derechas sudamericanas, 19171973. Los Polvorines: Ediciones de la UNGS.

Broquetas, Magdalena (2014). La trama autoritaria. Derechas y violencia en Uruguay (1958-1966). Montevideo: Ediciones de la Banda Oriental.

Caimari, Lila (2012). Mientras la ciudad duerme. Pistoleros, policías y periodistas en Buenos Aires, 1920-1945. Buenos Aires: S.XXI.

Camarero, Hernán (2008). Comunismo y movimiento obrero en la Argentina, 19141946. (Tesis de Doctorado). Facultad de Filosofía y Letras-UBA, Buenos Aires.

Camarero, Hernán y Herrera, Carlos Miguel (comps.) (2015). El Partido Socialista. Sociedad, política e ideas a través de un siglo. Buenos Aires: Prometeo.

Casals Araya, Marcelo (2016). La creación de la amenaza roja. Del surgimiento del anticomunismo en Chile a la «campaña del terror» de 1964. Santiago de Chile: LOM.

Ceruso, Diego (2015). La izquierda en la fábrica. La militancia obrera industrial en el lugar del trabajo, 1916-1943. Buenos Aires: Imago Mundi - Colección Archivos. 
Construir un enemigo en tiempos de neutralidad: anticomunismo y disciplinamiento detrás de los debates por el derecho de reunión en Argentina (1938-1943)

Devoto, Fernando (2002). Nacionalismo, fascismo y tradicionalismo en la Argentina moderna. Buenos Aires: S. XXI.

Ferreyra, Alejandra (2016). Las misiones de propaganda enviadas por el franquismo a la Argentina durante la Guerra Civil española (1936-1939). Cuadernos de Marte (11).

Ferreyra, Alejandra (2016). La acción propagandística a favor del Franquismo durante la Guerra Civil española: la actuación de Juan Pablo de Lojendio en Buenos Aires (1936-1939). Páginas (16).

Finchelstein, Federico (2010). El fascismo transatlántico. Ideología, violencia y sacralidad en la Argentina transatlántica, 1914-1945. Buenos Aires: FCE.

Friedmann, German (2010). Alemanes antinazis en la Argentina. Buenos Aires: SXXI.

Galeano, D. y Albornoz, Martín (2017). Anarquistas y policías en el atlántico sudamericano: una red transnacional, 1890-1910. Boletín del IHAA "Ravignani" (47).

González Aleman, Marianne (2011). ¿Qué hacer con la calle? La definición del espacio público porteño y el edicto policial de 1932. Boletín del IHAA "Ravignani" (34).

Iñigo Carrera, Nicolás (2016). La otra estrategia. La voluntad revolucionaria (19301935). Buenos Aires: Imago Mundi.

Kalmanowiecki, Laura (1997). Military Power and Policing in Argentina 1900-1955 (PHD Thesis).New School for Social Research: New York.

Kalmanowiecki, Laura (2000). Origins and applications of political policing in Argentina. Latin America Perpectives (2).

Kalmanowiecki, Laura (1998). Soldados ou Missionários domésticos? Ideologias y autoconcepções da Polícia Argentina. Estudos Historicos (22).

López, Ignacio (2016). Dos presidentes en la "tormenta del mundo". La política argentina en tiempos de Roberto Ortiz y Ramón Castillo (1938-1943) (Tesis Doctoral). UTDT, Buenos Aires.

López Cantera, Mercedes (2018). La representación obrera en disputa. El anticomunismo argentino en los conflictos de 1936 y 1937. Conflicto Social (19).

López Cantera, Mercedes (2015). La estrategia del comunismo argentino en la mirada del nacionalismo reaccionario durante la década de 1930. Páginas (15). 


\section{Mercedes F. López Cantera}

López Cantera, Mercedes (2014a). Detrás del debate. La cuestión comunista y la criminalización en la Ley de Represión al comunismo de 1936. Contenciosa (3).

López Cantera, Mercedes (2014b). Criminalizar al rojo. La represión al movimiento obrero en los informes de 1934 sobre la Sección Especial. Archivos de historia del movimiento obrero y la izquierda (4).

Morgenfeld, Leandro (2011). Vecinos en conflicto. Argentina y EEUU en las Conferencias Panamericanas 1880-1955. Buenos Aires: Peña Lillo-Continente.

Montenegro, Silvina (2002). La Guerra Civil española y la política argentina (Tesis Doctoral). Universidad Complutense de Madrid, Madrid.

Newton, Ronald (1995). El cuarto lado del triangulo. La "amenaza nazi" en la Argentinas (1931-1947). Buenos Aires: Sudamericana.

Patto Sá Motta, Rodrigo (2000). Em guarda contra o perigo vermelho: o anticomunismo no Brasil (1917-1964) (Tesis doctoral). Universidad de Sao Paulo, Sao Paulo.

Piro Mittelman, Gabriel (2018). El giro neutralista. El Partido Comunista argentino y su política frente a los inicios de la Segunda Guerra Mundial (1939-1941) (Tesis de Licenciatura). Facultad de Filosofía y Letras - UBA, Buenos Aires.

Potash, Robert (1981). El Ejército y la política en la Argentina. De Yrigoyen a Perón. Buenos Aires: Sudamericana.

Rodríguez Molas, Ricardo (1985). Historia de la Tortura y el Orden Represivo en la Argentina. Buenos Aires: EUDEBA.

Romero, Luis Alberto (1998). La sociedad argentina y el auge y caída del Tercer Reich, 1933-1945. Buenos Aires, AAVV, Informe Final CEANA.

Rouquié, Alan (1978). Poder militar y sociedad política en la Argentina, I. Buenos Aires: Emecé.

Visacovsky, Nerina (2015). Argentinos, judíos y camaradas tras la utopía socialista. Buenos Aires: Biblos.

Recibido: 25/09/2019

Evaluado: 30/10/2019

Versión Final: 15/11/2019 